\title{
Lab-Supported Hypothesis and Mathematical Modeling of Crack Development in the Fluid-Soaking Process of Multi-Fractured Horizontal Wells in Shale Gas Reservoirs
}

\author{
Zhiyong Huang ${ }^{1}\left(\mathbb{D}\right.$, Boyun Guo $^{2, *} \mathbb{C}$ and Rashid Shaibu ${ }^{2}$ \\ 1 School of Microelectronics and Communication Engineering, Chongqing University, Chongqing 400044, \\ China; zyhuang@cqu.edu.cn \\ 2 Department of Petroleum Engineering, University of Louisiana at Lafayette, Lafayette, LA 70504, USA; \\ rashid.shaibu1@louisiana.edu \\ * Correspondence: guo.boyun@gmail.com
}

Received: 23 December 2019; Accepted: 24 February 2020; Published: 26 February 2020

\begin{abstract}
The objective of this study is to develop a technique to identify the optimum water-soaking time for maximizing productivity of shale gas and oil wells. Based on the lab observation of cracks formed in shale core samples under simulated water-soaking conditions, shale cracking was found to dominate the water-soaking process in multi-fractured gas/oil wells. An analytical model was derived from the principle of capillary-viscous force balance to describe the dynamic process of crack propagation in shale gas formations during water-soaking. Result of model analysis shows that the formation of cracks contributes to improving well inflow performance, while the cracks also draw fracturing fluid from the hydraulic fractures and reduce fracture width, and consequently lower well inflow performance. The tradeoff between the crack development and fracture closure allows for an optimum water-soaking time, which will maximize well productivity. Reducing viscosity of fracturing fluid will speed up the optimum water-soaking time, while lowering the water-shale interfacial tension will delay the optimum water-soaking time. It is recommended that real-time shut-in pressure data are measured and shale core samples are tested to predict the density of cracks under fluid-soaking conditions before using the crack propagation model. This work provides a shut-in pressure data-driven method for water-soaking time optimization in shale gas wells for maximizing well productivity and gas recovery factor.
\end{abstract}

Keywords: shale; gas; fracture; shut-in; soaking; modeling

\section{Introduction}

Multi-fractured shale gas/oil wells with high water recoveries after hydraulic fracturing are normally low-productivity wells, while those with $10 \%$ to $40 \%$ water recoveries are normally high-productivity wells. The water loss into the formation does not hinder the gas/oil flow into the wellbore. Ehlig-Economides and Economides [1] attributed this effect to the, "water as proppant". Some shale gas and oil wells undergo month-long shut-in times after multi-stage hydraulic fracturing well stimulation. Such shut-in episodes increase the gas and oil flow rate. The mechanism behind it is not well understood.

Makhanov et al. [2] investigated spontaneous imbibition in shale formations at the lab scale and found the rate of fluid imbibition to be a function of the type and concentration of salts, surfactants, and viscosifiers. Anionic surfactant was shown to impede imbibition rate and the effect becomes pronounced with the addition of salt, such as $\mathrm{KCl}$, to the surfactant solution. A suggested approach to 
predict field observations from lab data indicated that low fracturing fluid recovery after shut-in period is in part due to spontaneous imbibition of water into the shale matrix-a phenomenon which depends on fluid/shale properties, fracture-matrix interface, and soaking time. They observed that for clay-rich organic shales, considerable spontaneous imbibition could occur for viscous solution-the explanation being the preferential adsorption of water molecules by clay particles. A similar observation was made by Zolfaghari et al. [3] when they studied the role of clays on water sorption behavior of gas shale samples.

Fakcharoenphol et al. [4] conducted numerical experiments to explore the consequences of long shut-in times on initial gas production rate and water load recovery in shale gas reservoirs. Their simulations supported some field observations of increased gas and oil rates after long shut-in periods. Osmotic pressure, capillary pressure, matrix wettability, and relative permeability were identified as key parameters affecting such increase in production after shut-in. They concluded that the observed lower flowrates immediately after fracturing is due to the fracture network being saturated with water which obstructs gas or oil flow. During shut-in, the injected water moves into the shale matrix - a mechanism controlled by gravity, capillary and/or osmotic pressure. A reduction in water saturation within the fractures allows higher gas flowrates. This increase in flowrate occurs for only a short period and is pore connectivity dependent.

Noe and Crafton [5] evaluated the effect of early production schedule on well productivity in over 270 wells. They analyzed the impacts of the period between multistage fracture stimulation and first production and well shut-in after first production on well productivity. Their results and conclusions were contrary to the conclusions reached by Fakcharoenphol et al. [4], as described above, and by other researchers [6]. Relying on hourly/daily rates and pressures data, they found that delay in first production and subsequent shut-ins are in fact detrimental, contrary to the perceived benefits derived from these management procedures. There was, however, a view in that, with regards to shut-in, the effects are usually, but not always, harmful. Damage arising from shut-in accumulates for each subsequent shut-in episode and in the long term provides poor reservoir-wellbore connectivity. However, there is no relationship between shut-in time and severity of the resulting damage. It is of their view that, the damage arising from the delays and shut-in could be mitigated by use of adequate concentration of an interfacial tension modifier fluid to minimize the influence of pressure-related energy consumed in interfacial tension and fluid/solid contact angles.

Javadpour et al. [7] presented experimentally obtained permeabilities of 152 samples from nine shale gas reservoirs with pore-size distribution of several shale samples at 60,000-psi mercury injection pressure. This tends not to support the hypothesis of imbibition as a dominating mechanism of soaking. Wu et al. [8] showed extremely slow processes of fluid flow in shale. The time required to seep through matrix with $10^{-9} \mathrm{~m}^{2}$ permeability for $1 \mathrm{~cm}$ distance is more than 100 years.

McClure and Zoback [9] observed an increase in Initial Shut-In Pressure (ISIP) from the toe to heal of five Barnett shale wells during multistage hydraulic fracturing treatment. For wells experiencing greater shut-in times, the increasing trend was minimal. Using calculations and numerical simulations, they concluded that stress shadowing could be a cause for the observed trends, but cannot be the only factor, or else there would have been an observed plateau after some stages of fracturing. Heterogeneity in formation properties and variations in operational parameters, such as proppant schedule, could be contributing factors.

Sinha et al. [10] proposed shut-in practices for dry gas shale reservoirs based on a study of wells in Marcellus shale. They postulated that an increase of water saturation in the shale matrix during shut-in causes permeability impairment and ultimately reduction in gas rates. The study also showed that the length of time of shut-in, and period in the life of the well in which the shut-in is planned, is critical to well productivity. They concluded that later shut-in has less impact than early shut-in on well productivity.

Clay minerals in shale samples preferentially imbibe water-an observation corroborated by Makhanov et al. [2] creating microfractures and a mechanism, which increases porosity and permeability 
and effectively enhances gas flow rates. To support this hypothesis, Gupta et al. [11] conducted laboratory experiments to measure the strain and stress induced by water imbibition in gas shale. Their results showed an increase in the porosity of the shale samples and a reduction in water imbibition rate when stress is applied to the shale samples.

In summary, different hypotheses/theories have been proposed to interpret the phenomena of increased productivity of multi-fractured wells in shale gas/oil reservoirs due to well shut-in. They include the matrix imbibition, stress shadow, and micro-fracture imbibition. These hypotheses/theories are conflicting and not thorough enough to be applied to analysis of the behavior of fractured shale gas/oil wells.

On the basis of laboratory observation, this paper presents a theory of dynamic post-frac cracking of shale rocks and its effect on productivity of shale gas/oil wells. The result presented in this paper demonstrates that the cracking of shale rocks during the "soaking" period is responsible for further stimulation of shale rocks in the fractured regions and thus for increasing well productivity. The optimum shut-in time can be determined using real time well pressure observed during the shut-in period. A data-driven approach to finding the optimum shut-in time has been developed for field applications.

\section{Laboratory Observations}

Clay-rich cores from the producing interval of a well in Louisiana were tested in our laboratory for its reactions to water and ceramic proppants. The tested cores were cut from larger core samples drilled by conventional means and well preserved at room conditions against absorption of moisture-they were wrapped in transparent plastic stretch films and kept in large zip lock bags. The cores were used for the experiments in their original state; thus, they were neither oven dried nor saturated with any fluid. The core characteristics and mineralogy are shown in Table 1 and Figure 1 respectively, indicating that the core is from a high-clay content shale. This is confirmed by the recent work by Borrok et al. [12].

Figure 2 shows the experimental design where Figure 2a presents a flow sketch, Figure $2 \mathrm{~b}$ displays the core sample placed in the core holder, Figure 2c illustrates the splitted shale core sample simulating hydraulic fractured shale, and Figure 2d demonstrates 20/40 ceramic proppant placed between the splitted core parts to simulate a hydraulic fracture. Test 1 was carried out with a proppant density of $0.2 \mathrm{lbm} / \mathrm{ft}^{2}$ under $500 \mathrm{psi}$ and 1000 psi confining pressures at water injection rates of $5 \mathrm{cc} / \mathrm{min}, 15 \mathrm{cc} / \mathrm{min}$, and $30 \mathrm{cc} / \mathrm{min}$. Test 2 was performed with a proppant density of $0.11 \mathrm{lbm} / \mathrm{ft}^{2}$ under 1000 psi confining pressure at a water injection rate $30 \mathrm{cc} / \mathrm{min}$. These experimental parameter values were selected to test fracture conductivity and proppant embedment, not specifically for fluid soaking, as soaking test does not require flowing fluids.

Table 1. Characteristics of the Shale Core.

\begin{tabular}{ccc}
\hline Parameter & Value & Units \\
\hline Core Depth & $15,183($ TVD $)$ & $\mathrm{ft}$ \\
\hline Weight & 0.68 & $\mathrm{lbm}$ \\
Diameter & 0.16 & $\mathrm{ft}$ \\
Length & 0.21 & $\mathrm{ft}$ \\
Density & 162.94 & $1 \mathrm{bm} / \mathrm{ft}^{3}$ \\
Matrix Permeability & 0.000084 & $\mathrm{mD}$ \\
Effective porosity & 3.25 & $\%$ \\
Total Organics Content & 1.55 & $\% \mathrm{wt}$ \\
\hline
\end{tabular}




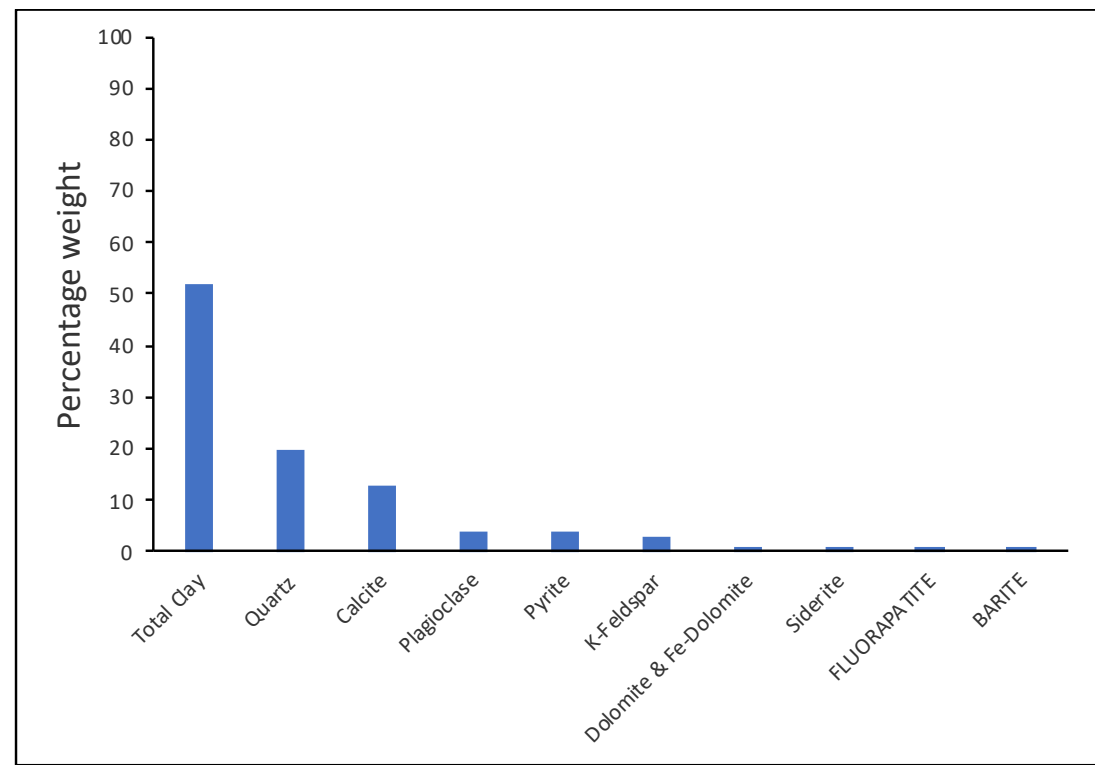

Figure 1. Mineralogy of tested shale core.

(a)

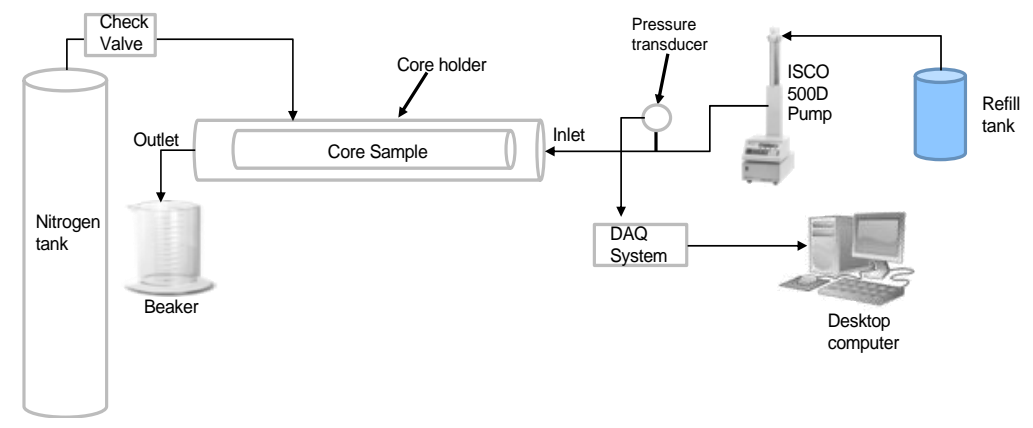

(b)

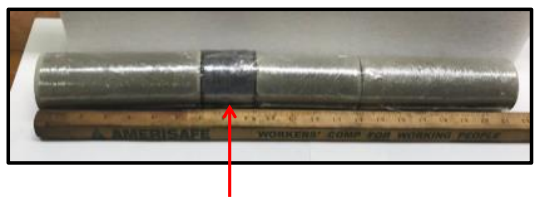

Shale core sample

(c)

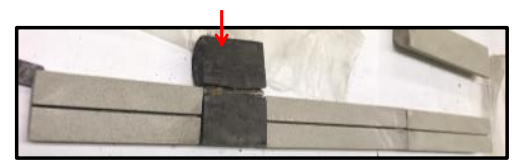

(d)

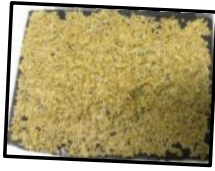

Figure 2. Experimental design for testing the reactions of a shale core to water and ceramic proppant under reservoir pressures. (a) flow sketch, (b) core sample in core holder, (c) splitted shale core sample, and (d) ceramic proppant between the splitted core parts.

Both of the tests were run for 10 hours. Figure 3 presents result of Test 2 where Figure 3 a illustrates a splitted core parts before testing, Figure $3 \mathrm{~b}$ displays the proppant embedment marks and a crack after testing, and Figure $3 \mathrm{c}$ shows four cracks along the bedding plane after testing (two cracks per inch of diameter).

The shale core sample was found relatively dry except the wet cracks. It is believed that water imbibed into the shale core in form of cracks, not seepage into the matrix. Therefore the term "soaking" is misleading. However, this term is still used in this work because it has been commonly adopted by researchers to interpret the loss of fracturing fluid into shale gas/oil formations. The fluid soaking owing to loss of fluid into cracks in shale is also evidenced in drilling operations. Aston et al. [13] 
proposed a treatment for wellbore strengthening in shale using nanoparticles to seal near wellbore cracks. The mechanism was revisited by Contreras et al. [14].

(a) Splitted core sample before testing

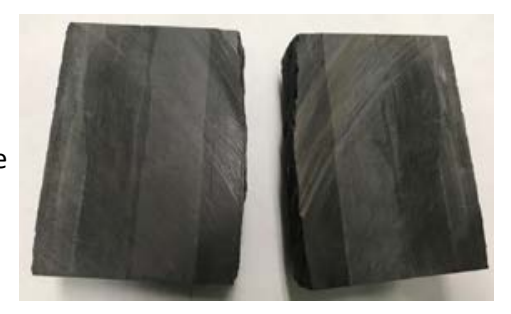

(b) Proppant embedment marks and crack

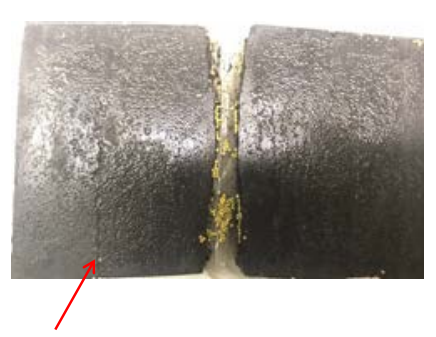

Crack along the bedding plane

(c) Horizontal cracks

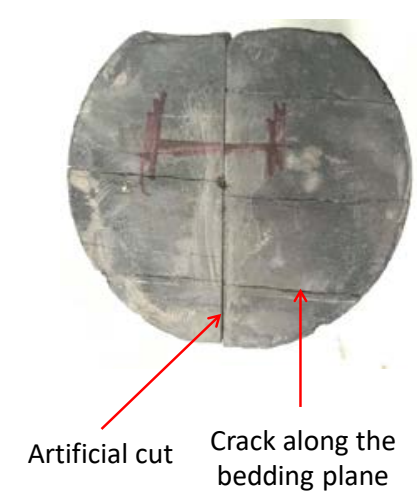

Figure 3. Appearance of shale core sample before and after testing.

\section{Mathematical Model}

This section presents an analytical model to describe the propagation of cracks in shale gas/oil formations during the soaking process in multi-stage fractured horizontal wells. Potential applications of the model and data requirement are also discussed.

Crack Propagation Model. A mathematic model for crack propagation was developed on the basis of assumed system configuration of hydraulic fractures and shale cracks in multi-stage fractured horizontal wells shown in Figure 4, where only three fractures and a few shale racks are illustrated. On the principle of force balance between capillary pressure and frictional pressure in a crack, the following Equation is derived in Appendix A for describing crack penetration depth:

$$
x_{c}=\left(\frac{1.59 V_{c}}{n_{f} n_{c}}\right)^{2 / 3}\left[\frac{\sigma \cos \theta\left(1-S_{w}\right)^{m}}{\mu q_{c} L_{c}}\right]^{1 / 3}
$$

where $x_{c}$ is crack depth in $\mathrm{ft}, V_{c}$ is crack volume (fluid loss to the shale formation) in $\mathrm{ft}^{3}, n_{f}$ is number of hydraulic fractures, $n_{c}$ is number of cracks, $\sigma$ is interfacial tension in dyne/ $\mathrm{cm}, \theta$ is contact angle in degree, $S_{w}$ is water saturation in shale (fraction), $m$ is saturation exponent, $\mu$ is viscosity of fracturing fluid in cp, $q_{c}$ is volumetric flow rate of fracturing fluid in crack in ft/day, and $L_{c}$ is crack length in $\mathrm{ft}$ (assumed to be equal to fracture length). The dynamic crack width is expressed by

$$
w_{c}=\sqrt{\frac{56.61 \mu q_{c}\left(\frac{1.59 V_{c}}{n_{f} n_{c}}\right)^{2 / 3}\left[\frac{\sigma \cos \theta\left(1-S_{w}\right)^{m}}{\mu q_{c} L_{c}}\right]^{1 / 3}}{L_{c} \sigma \cos \theta\left(1-S_{w}\right)^{m}}}
$$

where $w_{c}$ is the dynamic crack width in inch. 


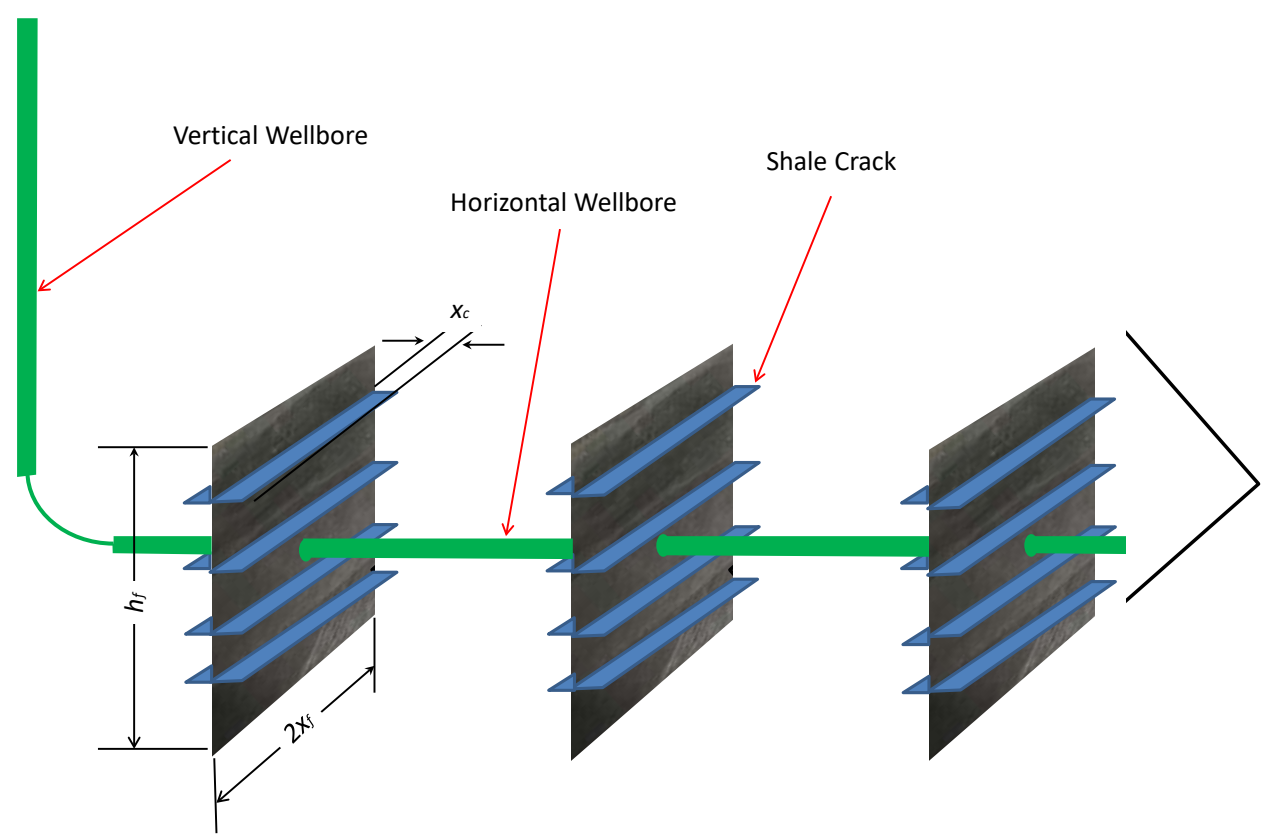

Figure 4. Configuration of hydraulic fractures and cracks during the fluid-soaking process.

\subsection{Potential Applications}

The crack propagation model can be applied to identification of the optimum soaking time for maximizing well productivity. The shale cracks developed in soaking process provide flow paths for gas/oil to flow from shale matrix to hydraulic fractures, which is expected to improve well inflow performance, while the loss of fracturing fluid into the cracks also results in the partial closure of hydraulic fractures, which reduces well inflow performance. There exists an optimum soaking time at which the adequate depth of crack is achieved while the hydraulic fractures are still open enough for effectively transporting gas and oil. The reduction in hydraulic fracture width is predicted by (see Appendix A for derivation):

$$
\Delta w_{f}=\frac{n_{c} L_{c} w_{c} x_{c}}{2 h_{f} x_{f}}
$$

where $\Delta w_{f}$ is reduction in fracture width.

A term called fold of increase $(F o I)$ is used in this study to evaluate well productivity improvement owing to water soaking. The FoI is defined as

$$
F o I=\frac{\text { well productivity index with water soaking }}{\text { well productivity index without water soaking }}
$$

Mathematical expression of the FoI is (see Appendix B for derivation):

$$
F O I=\sqrt{\left(1-\frac{\Delta w_{f}}{w_{f}}\right)\left(1+\frac{n_{c} L_{c} x_{c}}{2 h_{f} x_{f}}\left(\frac{k_{v}}{k_{h}}\right)\right)}
$$

Plotting the FoI in real soaking time will allow identifying the time when the FoI is maximal. This is the time expected to start the flowback process and well production.

\subsection{Data Requirement}

In order to apply the mathematical model to identification of the optimum soaking time, data for model parameters are required. The most crucial data are the real-time well shut-in pressure. If positive well head pressure is not observed, the real-time bottom hole pressure needs to be obtained. 
Unfortunately, this data set is not measured and recorded real-time in today's industry. Suppose this data set is continuously measured, the dynamic crack volume (fluid loss to the shale formation) $V_{c}$ in Equations (1)-(2) can be calculated by (see derivation in Appendix A):

$$
V_{c}=c_{f} V_{f}\left(p_{s i}-p\right)
$$

where $c_{f}\left(\mathrm{psi}^{-1}\right)$ is compressibility of fracturing fluid, $V_{f}\left(\mathrm{ft}^{3}\right)$ is total pumped volume of fracturing fluid in the fractures and wellbore, $p_{s i}$ (psi) is the initial shut-in pressure, and $p$ (psi) the shut-in pressure at soaking time. The dynamic flow rate in crack $q_{c}$ in Equations (1) and (2) can be calculated by (see derivation in Appendix A):

$$
q_{c}=-\frac{c_{f} V_{f}}{n_{f} n_{c}} \frac{d p}{d t}
$$

where the dynamic rate of pressure decline $d p / d t$ can be numerically calculated using the real-time pressure data $p$.

The analytical crack model assumes that all cracks initiate on the first day of soaking. The number of cracks may be estimated on the basis of soaking test in laboratory with real shale cores from the fractured interval and well logs that identify vertical heterogeneity in the interval. This requires additional studies.

\section{Case Analysis}

This section illustrates how to use the shale crack model and shut-in pressure data to identify the optimum soaking time in a shale play. Shut-in well pressure has seldom been measured during the water-soaking period. Kholy et al. [15] measured shut-in pressure for five hours after fracturing treatment to predict hydraulic fracture closure pressure. They found that the shut-in pressure declines linearly with time after a transition period beyond fracture closure. The shut-in time is too short to analyze soaking processes that commonly last a few weeks. Makhanov et al. [2] recorded shut-in pressure for 25 hours to estimate water loss during shut-in periods. They provided the best data set available for analyzing the soaking behavior in this section. The data reported in Makhanov et al.'s [2] paper are presented in Figure 5. Because the data were measured for only one day, the following correction was established to extrapolate to long shut-in time:

$$
p=4,460 t^{-0.044}
$$

where the shut-in bottom hole $p$ is in psia and the shut-in time $t$ is in hour. Table 2 presents data used in the analysis of shut-in pressure.

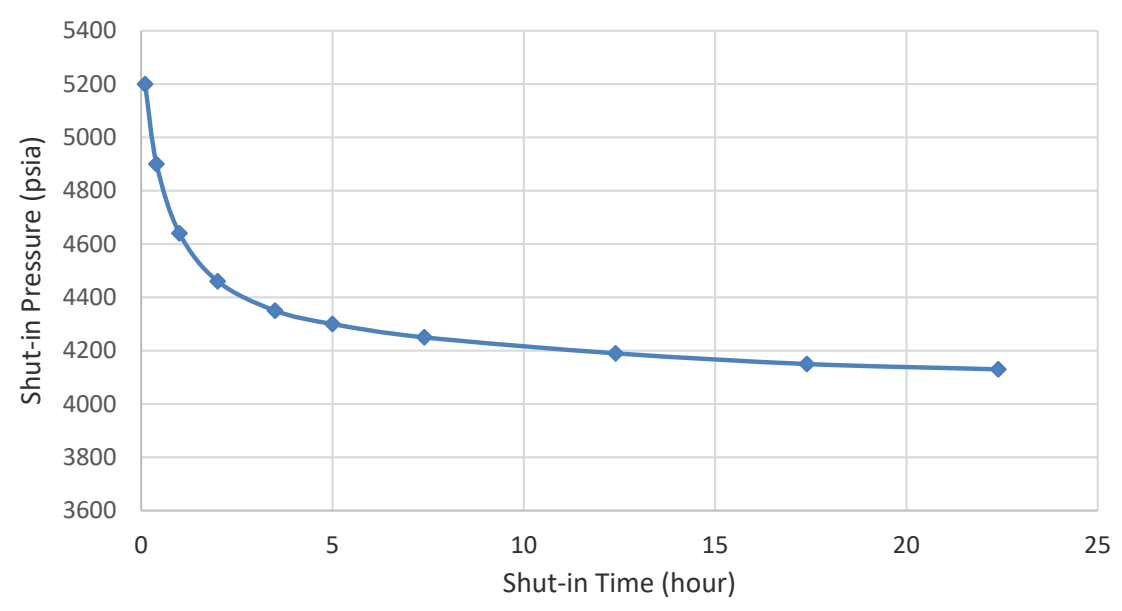

Figure 5. Shut-in pressure data reported by Makhanov et al. (2013). 
Table 2. Data Used in Shut-in Pressure Analysis and Soaking Time Recommendation.

\begin{tabular}{|c|c|c|}
\hline $\begin{array}{l}\text { Reservoir Horizontal } \\
\text { Permeability }\end{array}$ & 0.001 & md \\
\hline Reservoir vertical permeability & 0.0001 & md \\
\hline Number of hydraulic fractures & 100 & \\
\hline Average fracture half-length & 500 & $\mathrm{ft}$ \\
\hline Average fracture height & 200 & $\mathrm{ft}$ \\
\hline Total frac fluid volume & $6,216,000$ & gal \\
\hline Total proppant weight & $14,480,800$ & $\mathrm{lb}$ \\
\hline Proppant placement concentration & 0.72 & $\mathrm{lb} / \mathrm{ft}^{\wedge}$ \\
\hline Initial fracture width & 0.50 & in \\
\hline Number of cracks per fracture & 800 & \\
\hline Average crack length & 1000 & $\mathrm{ft}$ \\
\hline Interfacial tension & 65 & dyne/cm \\
\hline Contact angle & 10 & $\operatorname{deg}$ \\
\hline Water saturation & 0.3 & \\
\hline Saturation exponent & 1 & \\
\hline Fluid viscosity & 1 & $\mathrm{cp}$ \\
\hline Fluid compressibility & 0.000003 & $1 / \mathrm{psi}$ \\
\hline
\end{tabular}

Figure 6 shows model-calculated crack penetration depth and the remaining fracture width. It indicates that shale crack propagates fast in the beginning and slows down due to flow friction. The hydraulic fracture width drops fast in the beginning and slows down due to the slow growth of cracks. It is understood that the supporting effect of proppant was not considered in the calculations. It is expected that early supporting of proppant should slow down the closure of fractures and thus the soaking process. Nevertheless, the effect of proppant can be reflected in the real shut-in pressure profile.

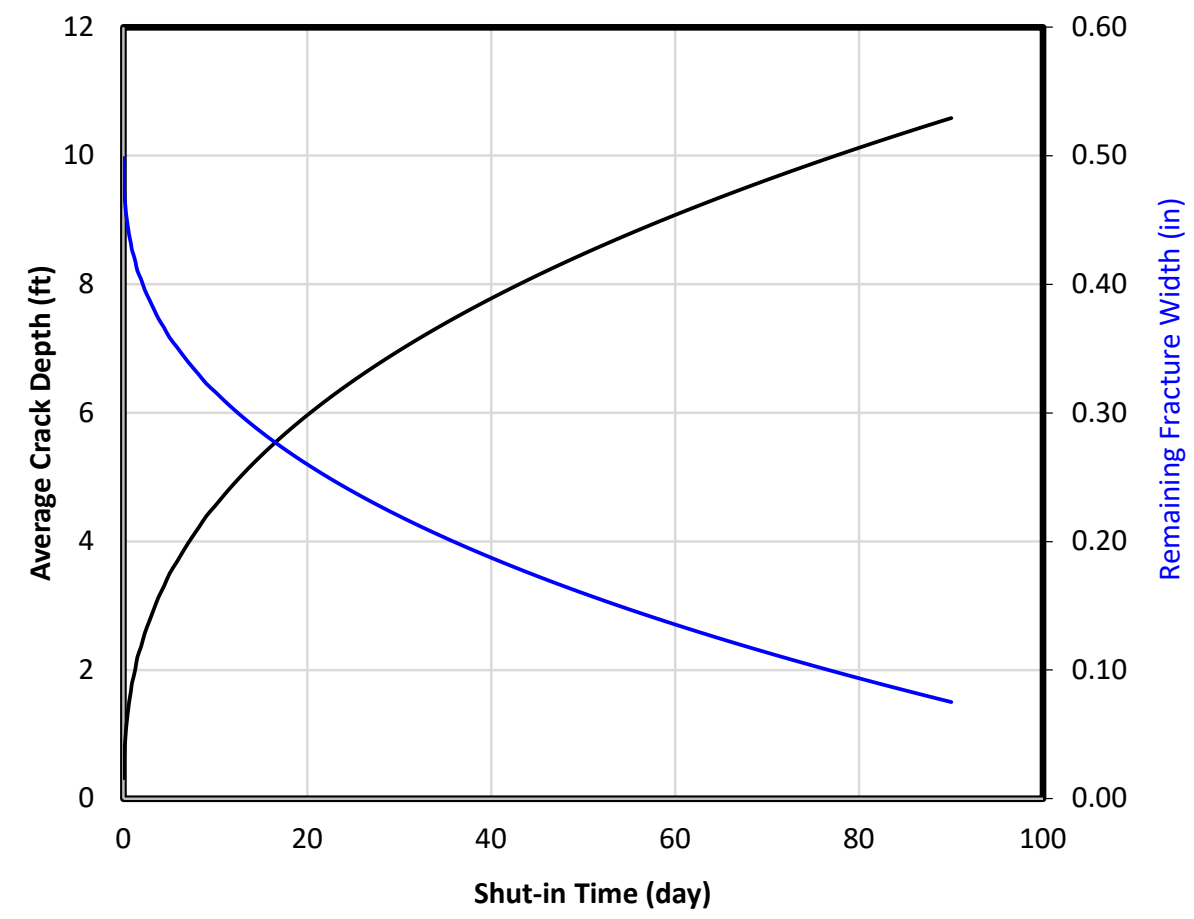

Figure 6. Model-calculated crack penetration depth and the remaining fracture width.

Figure 7 presents model-calculated fold of increase in well productivity due to fluid soaking. It suggests that the optimum soaking time is about 10 days. An FoI value of 1.34 is expected if the well is put on flowback and production after 10 days of soaking. Again, it is understood that the 
supporting effect of proppant was not considered in the calculations. This FoI value is expected if the adequate proppant is in place. However, the effect of proppant can be reflected in the real shut-in pressure profile.

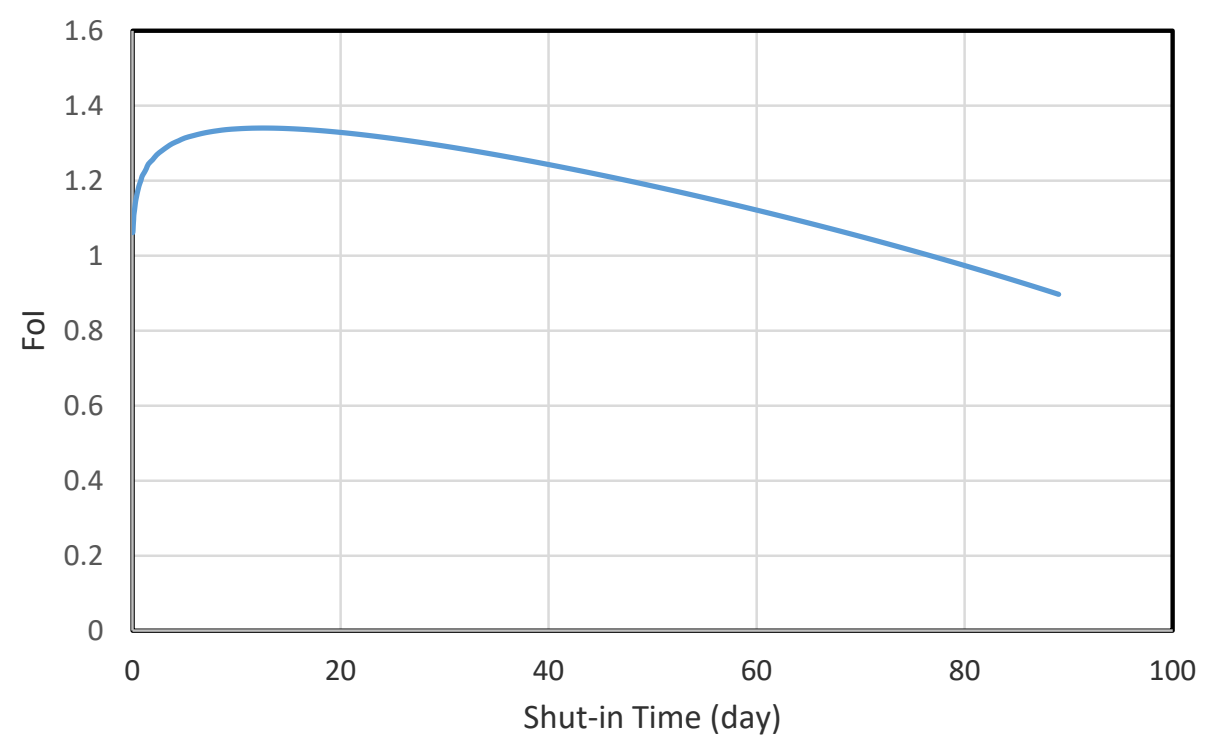

Figure 7. Model-calculated fold of increase in well productivity due to fluid soaking.

Figure 8 provides a comparison of the model-calculated folds of increase in well productivity for three scenarios having 400,600 , and 800 cracks per fracture. It shows that if the number of cracks per fracture drops to 600 and 400 , the optimum soaking time will be delayed to 21 days and 42 days, respectively.

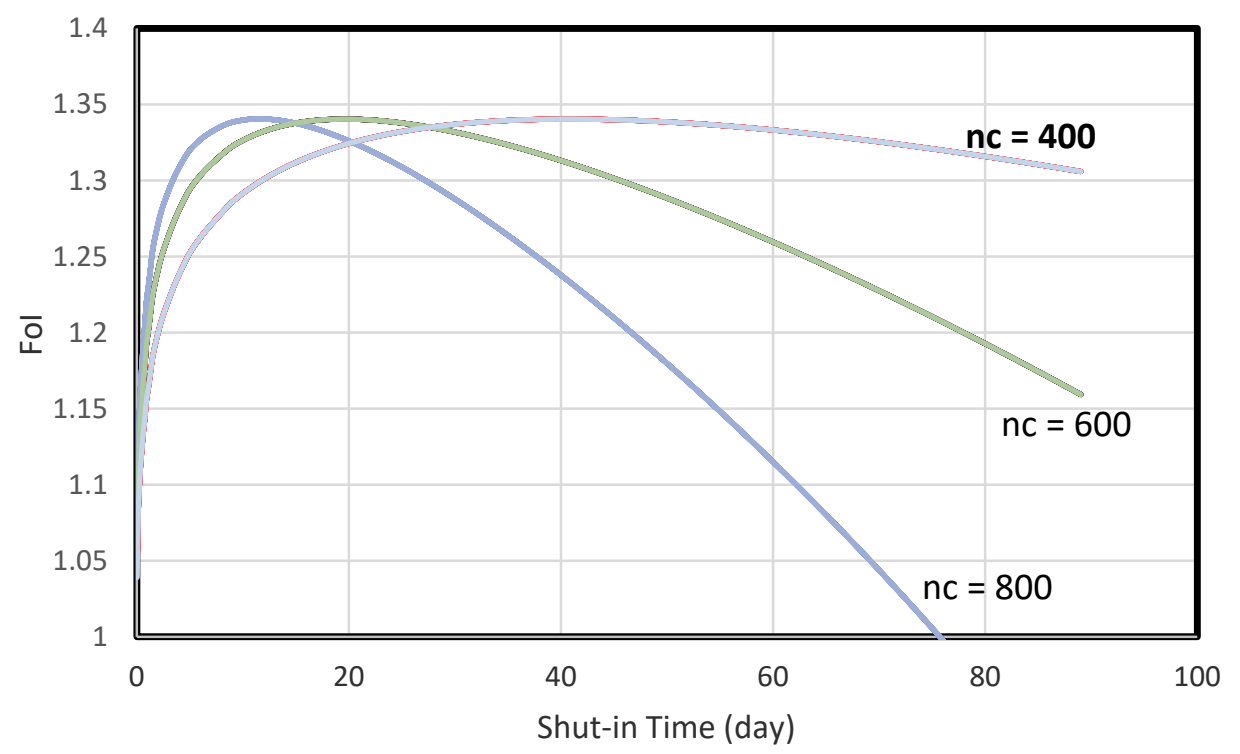

Figure 8. Effect of crack density (number of cracks per fracture) on the optimum soaking time.

Figure 9 shows the model-calculated effect of fluid viscosity on the on the optimum soaking time. If the fluid viscosity increases to $2 \mathrm{cp}$ and $3 \mathrm{cp}$, the optimum soaking time will be delayed to 22 days and 32 days, respectively. This is because fluid viscosity creates resistance to fluid flow during soaking. 


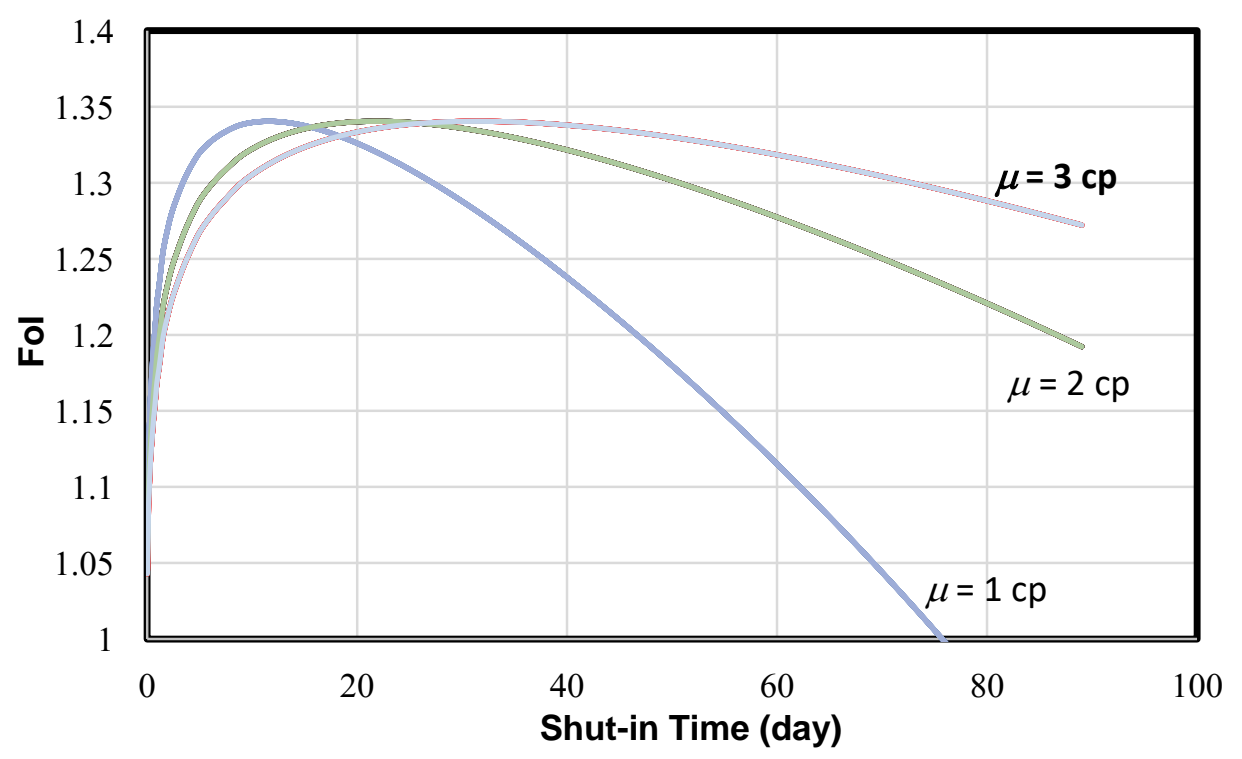

Figure 9. Effect of fluid viscosity on the optimum soaking time.

Figure 10 presents the model-calculated effect of fluid-shale interfacial tension on the optimum soaking time. If the interfacial tension is reduced to $45 \mathrm{dyne} / \mathrm{cm}$ and $25 \mathrm{dyne} / \mathrm{cm}$, the optimum soaking time will be delayed to 18 days and 28 days, respectively. This is because reducing interfacial tension lowers capillary pressure during soaking.

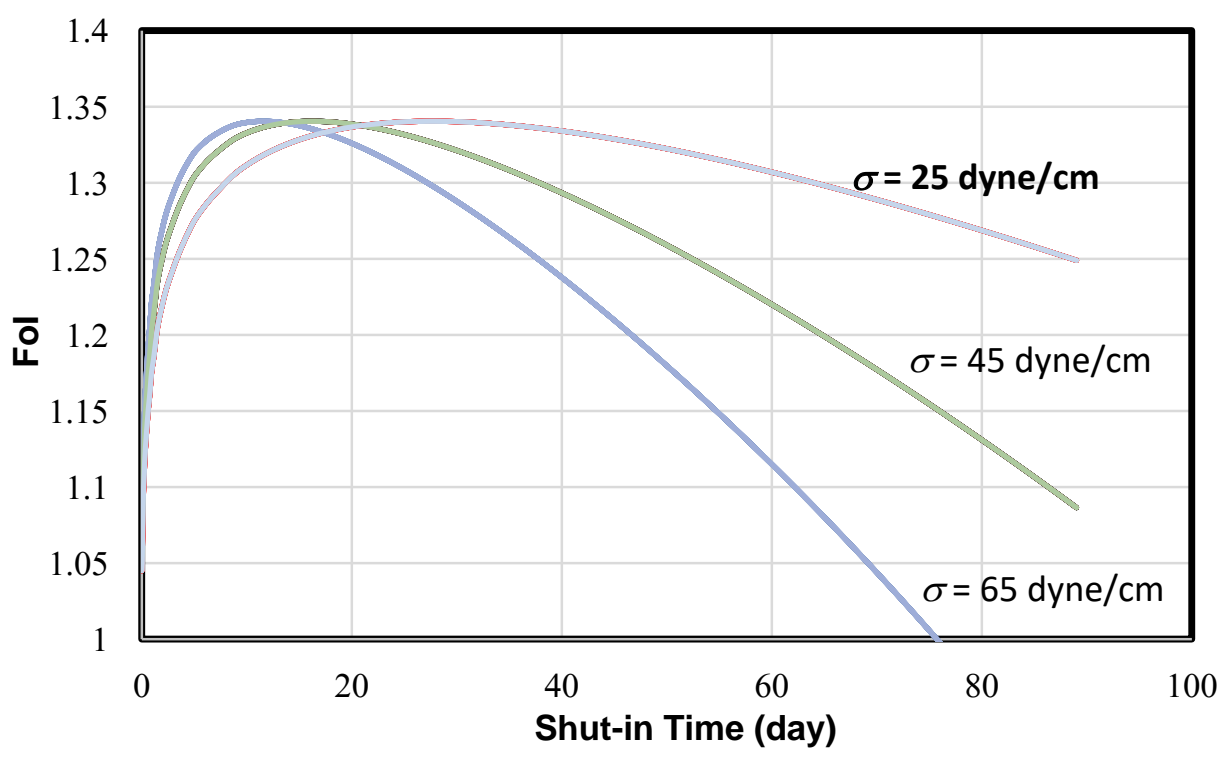

Figure 10. Effect of fluid-shale interfacial tension on the optimum soaking time.

\section{Discussion}

The tests were run at room temperature rather than reservoir temperature. Since temperature reduces interfacial tension and fluid viscosity, Equation (1) implies that tests at reservoir temperature would show low efficiency of water soaking because of low water-solid interfacial tension. However, Equation (1) also implies that reduction in water viscosity should promote water soaking. The tradeoff needs to be further investigated.

It is expected that different shale formation samples will have different test results depending on rock properties. Equation (1) shows that the crack formation depends on water saturation and 
contact angle. Shale formations with low water saturation but low contact angle should promote water soaking because of crack development.

The tests were run with 20/40 U.S.-mesh ceramic proppant, not the 100 U.S.-mesh sand, and 40/70 U.S.-mesh sand that are widely used in the industry for shale gas/oil wells. The reason was that the tests were also designed to investigate proppant embedment into the shale samples, which was believed to show clearer result with large proppant particles. Since none of the commercial proppant is believed to invade into the cracks during water soaking, it is anticipated that proppant size will not affect water-soaking efficiency. Nevertheless new tests are being conducted with finer proppant particles.

The strength of the proppant (ceramic proppant versus sand) is not expected to influence formation of cracks as long as the crushed proppant, if any, do not invade into the cracks during water soaking. This speculation needs further investigation though.

This work postulates a hypothesis that cracks are formed in shale formations after a hydraulic fracture stimulation and that they later contribute to improved well productivity. With some respective assumptions, mathematical models were developed to determine the optimum soaking time duration (period prior to start of flowback) and the theoretical effect of such cracks on the long-term productivity of shale gas and oil wells based on their previous work. Although the number of laboratory tests conducted is very limited and there is no field test performed yet, the hypothesis is believed relevant for well completion engineering on shale gas/oil formations. The result presented in the Example Calculations section is considered qualitative because of non-validated assumptions. The major assumption that may significantly affect the accuracy of the mathematical model is that the pressure decline during well shut-in is solely owing to crack development and not delayed by fracture closure, while fracture closure is accounted for in well productivity analysis.

The most crucial data required by the mathematical model is the real-time well shut-in pressure. The shut-in wellhead pressure prior to flowback is regularly recorded in several regions of the world but not globally. Measuring and recording well shut-in pressure data is not difficult and is feasible with today's technologies. It is recommended to continuously measure shut-in bottom hole pressure prior to flowback and test the mathematical model.

\section{Conclusions}

On the basis of observations of cracks formed in core samples under simulated water-soaking conditions, it is hypothesized that the soaking process during well shut-in in shale gas/oil wells involves initiation and propagation of cracks along the bedding plane driven by the capillary pressure. An analytical model was derived in this study to describe the dynamic process of crack propagation. The following conclusions are drawn from model analysis.

1. The propagation of cracks during the water-soaking process creates channels for gas/oil to flow from shale matrix to hydraulic fractures and thus contributes to improving well inflow performance. The propagation of cracks is a dynamic process with quick growth in the beginning and a slowing down with time.

2. The development of cracks draws fracturing fluid from the hydraulic fractures and reduces fracture width, and consequently lowers well inflow performance. The fracture width drops fast in the beginning and slows down with time.

3. The tradeoff between the crack development and fracture closure allows for an optimum soaking time, which will maximize well productivity. Reducing viscosity of fracturing fluid will speed up the optimum soaking time, while reducing the water-shale interfacial tension will delay the optimum soaking time.

4. Real-time shut-in pressure data can be processed with the crack propagation model to "monitor" crack development and identify the optimum soaking time before flowback of hydraulic fluids.

5. It is recommended that shale core samples be tested to predict the density of cracks under fluid-soaking conditions before using the crack propagation model. Real-time shut-in bottom 
hole pressure data should be measured to drive the crack propagation model for soaking time optimization

Author Contributions: Investigation, R.S.; Methodology, B.G.; Resources, Z.H.; Supervision, B.G.; Validation, B.G.; Writing - original draft, Z.H. All authors have read and agreed to the published version of the manuscript.

Acknowledgments: The authors gratefully acknowledge the partial financial support to this research work from the Pegasus Vertex, Inc.

Conflicts of Interest: The authors declare no conflict of interest.

\section{Appendix A : Crack Propagation During Shutting-in Multi-Fractured Shale Gas/Oil Wells}

The following assumptions are made in the mathematical modeling:

1. Fluid leak off into rock matrix is negligible during the shut-in period.

2. Cracks take rectangular shape in vertical plane.

3. Capillary force causes propagation of cracks.

4. Friction force resists the growth of cracks.

5. All cracks initiate at the beginning of well shut-in.

When the shut-in wellhead pressure drops from the initial value $p_{s i}(\mathrm{psi})$ to $p$ (psi) at shut-in time $t$ (second), the expansion of fracturing fluid, which is equal to the volume of cracks $V_{c}\left(\mathrm{ft}^{3}\right)$ is expressed as

$$
V_{c}=c_{f} V_{f}\left(p_{s i}-p\right)
$$

where $c_{f}\left(\mathrm{psi}^{-1}\right)$ is the compressibility of fracturing fluid and $V_{f}\left(\mathrm{ft}^{3}\right)$ is the total volume of wellbore and fractures. Assuming $n_{\mathcal{c}}$ cracks are initiated in $n_{f}$ fractures, material balance gives

$$
V_{c}=\frac{1}{12} n_{f} n_{c} L_{c} w_{c} x_{c}
$$

where $x_{\mathcal{c}}(\mathrm{ft})$ is the dynamic penetration depth of crack, $w_{\mathcal{C}}(\mathrm{in})$ is dynamic width of crack, and $L_{\mathcal{c}}(\mathrm{ft})$ is length of crack (assumed to be fracture length as shown in Figure 3). Equation (A2) gives an expression of dynamic crack depth of

$$
x_{c}=\frac{12 V_{c}}{n_{f} n_{c} L_{c} w_{c}}
$$

In order to find another relation between $w_{c}$ and $x_{c}$, taking the derivative of Equation (A1) with respect to time $t$ gives:

$$
\frac{d V_{c}}{d t}=-c_{f} V_{f} \frac{d p}{d t}
$$

The left-hand-side of the Equation is the total leak off flow rate into all cracks. The average leak off flow rate to each crack is expressed as:

$$
q_{c}=-\frac{c_{f} V_{f}}{n_{f} n_{c}} \frac{d p}{d t}
$$

Due to the ultralow permeability nature of shale matrix and the fracturing time being much shorter than the soaking time during shut-in period, the fluid loss due to leak off is practically negligible. The flow rate of fracturing fluid in crack depends on the balance between the capillary pressure as the driving force and friction pressure as the resisting force. The capillary pressure is expressed by

$$
p_{c}=\frac{2(14.7) \sigma \cos \theta}{(2)(100,000)(2.54)(9.81) w_{c}}\left(1-S_{w}\right)^{m}=5.9 \times 10^{-6} \frac{\sigma \cos \theta}{w_{c}}\left(1-S_{w}\right)^{m}
$$


where the $p_{c}$ is capillary pressure (psi), $\sigma\left(\right.$ dyne/cm) is interfacial tension, $\theta$ contact angle, $S_{w}$ is water saturation (fraction) and $m$ is saturation exponent. The friction pressure is expressed as $[16,17])$ :

$$
p_{f}=\frac{(12) f_{f} \rho v_{c}^{2} x_{c}}{(144)(32.17) w_{c}}=2.59 \times 10^{-3} \frac{f_{f} \rho v_{c}^{2} x_{c}}{w_{c}}
$$

where the $p_{f}(\mathrm{psi})$ is friction pressure, $f_{f}$ is Fanning friction factor, $\rho\left(\mathrm{lb} / \mathrm{ft}^{3}\right)$ is fracturing fluid density and $v_{c}(\mathrm{ft} / \mathrm{s})$ is fluid velocity (also crack propagation velocity). Assuming laminar flow in crack, the friction factor is expressed as

$$
f_{f}=\frac{16}{N_{\operatorname{Re}}}
$$

where the Reynolds number $N_{R e}$ is given by

$$
N_{\operatorname{Re}}=124 \frac{w_{c} \rho v_{c}}{\mu}
$$

where $\mu$ (cp) is fluid viscosity. The fluid velocity in Equation (A7) is expressed by

$$
v_{c}=\frac{q_{c}}{L_{c} w_{c}}
$$

Substituting Equations (A8) through (A10) into Equation (A7) and rearranging the latter yield

$$
p_{f}=3.34 \times 10^{-4} \frac{\mu q_{c} x_{c}}{L_{c} w_{c}^{3}}
$$

Neglecting the inertial effect, the fraction force is equal to the capillary force. Equating Equations (A11) and (A6) gives

$$
5.9 \times 10^{-6} \sigma \cos \theta\left(1-S_{w}\right)^{m}=3.34 \times 10^{-4} \frac{\mu q_{c} x_{c}}{L_{c} w_{c}^{2}}
$$

which yields

$$
w_{c}=\sqrt{\frac{56.61 \mu q_{c} x_{c}}{L_{c} \sigma \cos \theta\left(1-S_{w}\right)^{m}}}
$$

Substitution of Equation (A13) into Equation (A3) gives

$$
x_{c}=\left(\frac{1.59 V_{c}}{n_{f} n_{c}}\right)^{2 / 3}\left[\frac{\sigma \cos \theta\left(1-S_{w}\right)^{m}}{\mu q_{c} L_{c}}\right]^{1 / 3}
$$

Substituting Equation (A14) into Equation (A13) and rearranging the latter result in

$$
w_{c}=\sqrt{\frac{56.61 \mu q_{c}\left(\frac{1.59 V_{c}}{n_{f} n_{c}}\right)^{2 / 3}\left[\frac{\sigma \cos \theta\left(1-S_{w}\right)^{m}}{\mu q_{c} L_{c}}\right]^{1 / 3}}{L_{c} \sigma \cos \theta\left(1-S_{w}\right)^{m}}}
$$

Due to the formation of cracks, the fracture width gets narrower. The reduction in fracture width is formulated by material balance:

$$
2 \Delta w_{f} h_{f} x_{f}=n_{c} w_{c} L_{c} x_{c}
$$

where the $\Delta w_{f}\left(\right.$ inch) is fracture width reduction, $h_{f}(\mathrm{ft})$ is fracture height, and $x_{f}(\mathrm{ft})$ is fracture half-length. This relation gives

$$
\Delta w_{f}=\frac{n_{c} L_{c} w_{c} x_{c}}{2 h_{f} x_{f}}
$$

where the $x_{c}$ and $w_{c}$ are given by Equations (A14) and (A15), respectively. 


\section{Appendix B : Initial Productivity of Multi-Fractured Shale Gas Wells with Shale Cracks}

Li et al.'s (2019) well productivity model for pseudo steady flow is extended to include the effect of shut-in time-dependent cracks prior to fluid flow back. Li et al.'s [18] gas well productivity model takes the following form:

$$
Q_{g}=\frac{5.87 \times 10^{-5} n_{f} k_{m} h\left(\bar{p}^{2}-p_{w}^{2}\right)}{\mu_{g} T S_{f} \sqrt{c}\left(\frac{1}{1-e^{-\sqrt{c} x_{f}}}-\frac{1}{3 x_{f} \sqrt{c}}\right)}
$$

where $Q_{g}$ is gas production rate in Mscf/d, $n_{f}$ is the number of fractures, $k_{m}$ is matrix permeability in $\mathrm{md}, h$ is pay zone thickness in $\mathrm{ft}, \bar{p}$ is the average formation pressure in psia, $p_{w}$ is wellbore pressure in psia, $\mu_{g}$ is gas viscosity in cp, $T$ is formation temperature in ${ }^{\circ} \mathrm{R}, S_{f}$ is fracture spacing in $\mathrm{ft}, e$ is the exponential function, $x_{f}$ is fracture half-length in $\mathrm{ft}, k_{f}$ is fracture permeability in $\mathrm{md}$, and $w_{f}$ is the average fracture width in inch, and

$$
c=\frac{96 k_{m}}{k_{f} w_{f} S_{f}}
$$

If $n_{c}$ cracks are developed during the shut-in time prior to flowback of hydraulic fluid, an equivalent permeability of the matrix can be defined as follows:

$$
k_{m e}=\frac{4 h_{f} x_{f} k_{h}+2 n_{c} L_{c} x_{c} k_{v}}{4 h_{f} x_{f}}
$$

or

$$
k m e=k h(1+n c L c x c 2 h f x f k v k h)
$$

where $h_{f}$ is fracture height in $\mathrm{ft}$, and $x_{c}$ and $w_{c}$ are given by Equations (A14) and (A15), respectively. If a reduced fracture width defined as follows is used

$$
w_{f r}=w_{f}-\Delta w_{f}=w_{f}\left(1-\frac{\Delta w_{f}}{w_{f}}\right)
$$

where $\Delta w_{f}$ is given by Equation (A17). For wells with cracks, Equations (A18) through (A19) becomes

$$
\begin{gathered}
Q_{g c}=\frac{5.87 \times 10^{-5} n_{f} k_{m e} h\left(\bar{p}^{2}-p_{w}^{2}\right)}{\mu_{g} T S_{f} \sqrt{c_{c}}\left(\frac{1}{1-e^{-\sqrt{c c} x_{f}}}-\frac{1}{3 x_{f} \sqrt{c_{c}}}\right)} \\
c_{c}=\frac{96 k_{m}\left(1+\frac{n_{c} L_{c} x_{c}}{2 h_{f} x_{f}}\left(\frac{k_{v}}{k_{h}}\right)\right)}{k_{f} S_{f} w_{f}\left(1-\frac{\Delta w_{f}}{w_{f}}\right)}=c \frac{\left(1+\frac{n_{c} L_{c} x_{c}}{2 h_{f} x_{f}}\left(\frac{k_{v}}{k_{h}}\right)\right)}{\left(1-\frac{\Delta w_{f}}{w_{f}}\right)}
\end{gathered}
$$

Therefore, Equation (A23) becomes

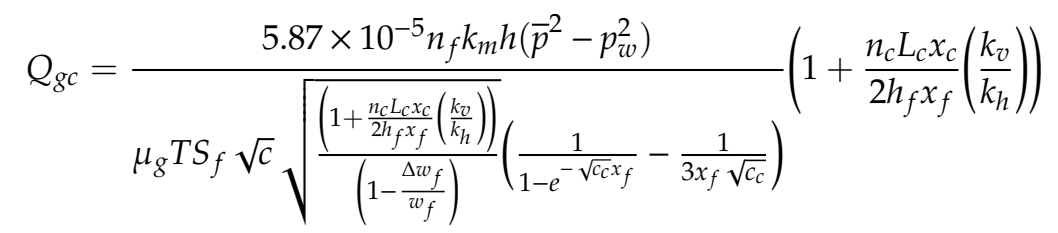

That is

$$
Q_{g c}=\frac{5.87 \times 10^{-5} n_{f} k_{m} h\left(\bar{p}^{2}-p_{w}^{2}\right)}{\mu_{g} T S_{f} \sqrt{c}\left(\frac{1}{1-e^{-\sqrt{c c} x_{f}}}-\frac{1}{3 x_{f} \sqrt{c_{c}}}\right)} \sqrt{\left(1-\frac{\Delta w_{f}}{w_{f}}\right)\left(1+\frac{n_{c} L_{c} x_{c}}{2 h_{f} x_{f}}\left(\frac{k_{v}}{k_{h}}\right)\right)}
$$


Dividing Equation (A26) by Equation (A18) yields a Fold of Increase (FoI) expressed by

$$
F o I=\sqrt{\left(1-\frac{\Delta w_{f}}{w_{f}}\right)\left(1+\frac{n_{c} L_{c} x_{c}}{2 h_{f} x_{f}}\left(\frac{k_{v}}{k_{h}}\right)\right)}
$$

The above-derived FoI theory is also valid for multi-stage hydraulic-fractured horizontal oil wells where well inflow performance is given by Li et al.'s [18] analytical model as follows:

$$
Q_{o}=\frac{5.91 \times 10^{-3} n_{f} k_{m} h\left(\bar{p}-p_{w}\right)}{B_{o} \mu_{o} S_{f} \sqrt{c}\left[\frac{1}{1-e^{-\sqrt{c} x_{f}}}-\frac{1}{\left.3 x_{f} \sqrt{c}\right)}\right)}
$$

where $Q_{o}$ is oil production rate in $\mathrm{stb} / \mathrm{d}, B_{o}$ is oil formation volume factor, and $\mu_{o}$ is oil viscosity.

\section{Nomenclature}

$B_{0}$

$c_{f}$

$f_{f}$

$h_{f}$

$k_{f}$

$k_{m}$

$L_{c}$

$m$

$n_{C}$

$n_{f}$

$p$

$p_{\text {si }}$

$p_{w}$

$\bar{p}$

$q_{c}$

$Q_{g}$

$Q_{g c}$

$Q_{0}$

$S_{f}$

$S_{w}$

$T$

$t$

$v_{c}$

$V_{c}$

$V_{f}$

$w_{c}$

$x_{c}$

$\rho$

$\mu$

$\mu_{g}$

$\mu_{o}$

$\sigma$

$\theta$ formation volume factor of oil, rb/stb

fracturing fluid compressibility, $\mathrm{psi}^{-1}$

Fanning friction factor, dimensionless

average height of hydraulic fractures, $\mathrm{ft}$

fracture permeability, $\mathrm{md}$

matrix permeability, md

length of crack, $\mathrm{ft}$

water saturation exponent, dimensionless

number of cracks per fracture

number of fractures per well

well shut-in pressure, psi

initial shut-in pressure, psi

wellbore pressure, $\mathrm{psi}$

average reservoir pressure, $\mathrm{psi}$

fluid flow rate in crack, $\mathrm{ft}^{3} /$ day

gas production rate of gas wells without fluid -soaking, Mscf/day

gas production rate of gas wells with fluid -soaking," Mscf/day

oil production rate, stb/day

fracture spacing, $\mathrm{ft}$

water saturation in shale matrix, fraction

reservoir temperature, ${ }^{\circ} \mathrm{R}$

shut-in time, day

velocity of fluid in the crack, $\mathrm{ft} / \mathrm{s}$

total volume of fluid in all cracks, $\mathrm{ft}^{3}$

total volume of fracturing fluid in the system, $\mathrm{ft}^{3}$

the average width of cracks, inch

the average penetration depth of cracks, $\mathrm{ft}$

density of fracturing fluid, $\mathrm{lbm} / \mathrm{ft}^{3}$

viscosity of fracturing fluid, $\mathrm{cp}$

viscosity of gas, $\mathrm{cp}$

viscosity of oil, $\mathrm{cp}$

interfacial tension, dyne $/ \mathrm{cm}$

contact angle, degree 


\section{References}

1. Ehlig-Economides, C.A.; Economides, M.J. Water as proppant. In Proceedings of the SPE Annual Technical Conference and Exhibition, Denver, CO, USA, 30 October-2 November 2011. paper SPE 147603.

2. Makhanov, K.; Dehghanpour, H.; Kuru, E. Measuring liquid uptake of organic shales: A workflow to estimate water loss during shut-in periods. In Proceedings of the SPE Unconventional Resources Conference Canada, Calgary, AB, Canada, 5-7 November 2013. [CrossRef]

3. Zolfaghari, A.; Dehghanpour, H.; Holyk, J. Water sorption behavior of gas shales: I. Role of clays. Int. J. Coal Geol. 2017, 179, 130-138. [CrossRef]

4. Fakcharoenphol, P.; Torcuk, M.A.; Wallace, J.; Bertoncello, A.; Kazemi, H.; Wu, Y.-S.; Honarpour, M. Managing shut-in time to enhance gas flow rate in hydraulic fractured shale reservoirs: A simulation study. In Proceedings of the SPE Annual Technical Conference and Exhibition, New Orleans, LA, USA, 30 September-2 October 2013. [CrossRef]

5. Noe, S.; Crafton, J.W. Impact of delays and shut-ins on well productivity. In Proceedings of the SPE Eastern Regional Meeting, Pittsburgh, PA, USA, 20-22 August 2013. [CrossRef]

6. Ghanbari, E.; Dehghanpour, H. The fate of fracturing water: A field and simulation study. Fuel 2016, 163, 282-294. [CrossRef]

7. Javadpour, F.; Fisher, D.; Unsworth, M. Nanoscale gas flow in shale gas sediments. J. Can. Pet. Technol. 2007, 46, 55-61. [CrossRef]

8. Wu, Q.; Xu, Y.; Wang, X.; Wang, T.; Zhang, S. Volume fracturing technology of unconventional reservoirs: Connotation, design optimization and implementation. Pet. Explor. Dev. 2012, 39, 377-384. [CrossRef]

9. McClure, M.W.; Zoback, M.D. Computational investigation of trends in initial shut-in pressure during multi-stage hydraulic stimulation in the barnett shale. In Proceedings of the 47th US Rock Mechanics/Geomechanics Symposium, San Francisco, CA, USA, 23-26 June 2013.

10. Sinha, S.; Marfurt, K.J.; Deka, B. Effect of frequent well shut-in's on well productivity: Marcellus shale case study. In Proceedings of the SPE Eastern Regional Meeting, Lexington, KY, USA, 4-6 October 2017. [CrossRef]

11. Gupta, A.; Xu, M.; Dehghanpour, H.; Bearinger, D. Experimental investigation for microscale stimulation of shales by water imbibition during the shut-in periods. In Proceedings of the SPE Unconventional Resources Conference, Calgary, AB, Canada, 15-16 February 2017. [CrossRef]

12. Borrok, D.M.; Yang, W.; Wei, M.; Mokhtari, M. Heterogeneity of the mineralogy and organic content of the Tuscaloosa Marine Shale. Mar. Pet. Geol. 2019, 109, 717-731. [CrossRef]

13. Aston, M.S.; Alberty, M.W.; Duncum, S.D.; Bruton, J.R.; Friedheim, J.E.; Sanders, M.W. A new treatment for wellbore strengthening in shale. In Proceedings of the SPE Annual Technical Conference and Exhibition, Anaheim, CA, USA, 11-14 November 2007. [CrossRef]

14. Contreras, O.; Hareland, G.; Husein, M.; Nygaard, R.; Al-saba Mortadha, T. Experimental investigation on wellbore strengthening in shales by means of nanoparticle-based drilling fluids. In Proceedings of the SPE Annual Technical Conference and Exhibition, Amsterdam, The Netherlands, 27-29 October 2014. [CrossRef]

15. Kholy, S.M.; Mohamed, I.M.; Loloi, M.; Abou-Sayed, O.; Abou-Sayed, A. Development of an empirical equation to predict hydraulic fracture closure pressure from the initial shut-in pressure after treatment. In Proceedings of the SPE Liquids-Rich Basins Conference-North America, Midland, TX, USA, 13-14 September 2017. [CrossRef]

16. Dorf, R.C. The Engineering Handbook; CRC Press: Boca Raton, FL, USA, 1995; pp. 1026-1027.

17. Geertsma, J.; de Klerk, F. A rapid method of predicting with and extent of hydraulic induced fractures. J. Pet. Technol. 1969, 21, 1571-1581. [CrossRef]

18. Li, J.; Guo, B.; Wang, M. A general mathematical model for predicting long-term productivity of modern multifractured shale gas/oil wells. SPE Drill. Complet. 2018, 34, 44-50.

(C) 2020 by the authors. Licensee MDPI, Basel, Switzerland. This article is an open access article distributed under the terms and conditions of the Creative Commons Attribution (CC BY) license (http://creativecommons.org/licenses/by/4.0/). 